\title{
Benefits and Challenges of Clinical Nurse Educator Roles: A Qualitative Exploratory Study
}

\author{
Siluh Nyoman Alit Nuryani ${ }^{1,2 *}$ D, Ida Bagus Putu Arnyana ${ }^{1}$, Ni Nyoman Parwati ${ }^{1}$, Gede Rasben Dantes ${ }^{1}$, I Gede Juanamasta ${ }^{3}$ (D \\ ${ }^{1}$ Doctoral Program on Educational Science, Ganesha University of Education, Bali, Indonesia; ${ }^{2}$ Nursing Committee, Sanglah \\ General Hospital, Bali, Indonesia; ${ }^{3}$ Department of Nursing, STIKes Wira Medika, Bali, Indonesia
}

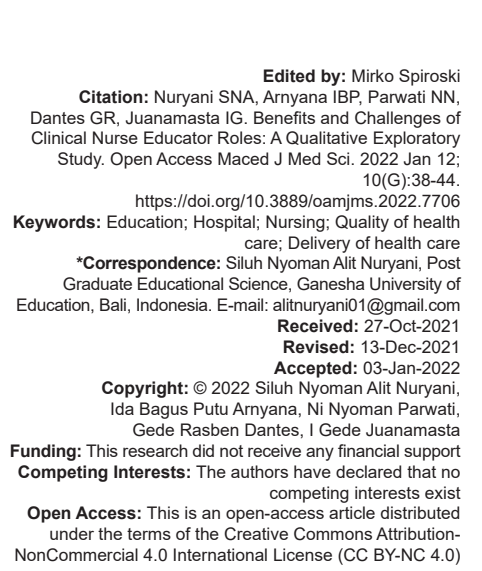

\section{Introduction}

Globally, the majority of health care is provided by nurses. Qualified nurses and professionals are required in the nursing field. Continuous improvement and ongoing professional development are expected for all nurses worldwide. Many countries have introduced clinical nurse educators (CNEs) who provide current bedside professional development to other nurses. CNEs refer to professional nurses who correctly appraises and evaluates nursing professional career plans, generally in a clinical area. Nurse educators should have high competency. They should own the broad experience of knowledge, abilities, and characters to adopt and apply new nurse education approaches [1]. Hence, nurse educators must continuously maintain and update the qualities and competencies with further information and technologies in line with technological advancements.

Based on hospitals' conditions of various working environments that caused the nurse educator's roles and authority remain unclear. They might have dualtask in the academic and clinical settings. This condition occurs in the United Kingdom (UK) and the USA [2], whereas nurse educators initially work in Australia's hospital setting. In Indonesia, this role was minimally regulated. In fact, that regulation from Ministry of Health number 40 in 2017 about the Indonesian nursing career pathway described clinical nurse as (perawat klinik/PK) career pathway from level one until level five [3], [4]. However, this policy has not yet described the career pathway for CNEs. The World Health Organization [1] had mentioned the role of CNE. It developed a minimum of eight core competencies for CNE should possess, including (1) adult learning theories and principles, (2) application and curriculum, (3) nursing practice, (4) evidence-based research, (5) communication, collaboration, and partnership, (6) professionalism and ethic, (7) management with monitoring and evaluation, (8) leadership and advocacy skills. Nevertheless, many terminologies that CNE should be prepared to provide effective teaching and learning for nurses.

One program implemented in Sanglah General Hospital (SGH) was the development of the role of CNE. This role was appointed for experienced clinical nurses with agreement from hospital management to act on these roles. They had been prepared for a short education program for 4 weeks at Royal Darwin Hospital (RDH) (June-July 2013) to enable them to become a CNE. This 4-week program involved face to face teaching sessions to expose them to principles of 
teaching and learning. Senior who has experienced of $\mathrm{CNE}$ is also mentoring them from $\mathrm{RDH}$ in the clinical area, which makes novice CNE had new perspectives and experiences of their role. After returning to $\mathrm{SGH}$, they were expected to provide teaching and learning for nurses. The study aimed to explore to explore the benefits and challenges of CNEs.

\section{Literature review}

\section{Definition and requirement of nurse educator}

CNE is a professional expert whose primary duty is to afford education to undergraduate, graduate, and postgraduate nursing students [2]. The role of a CNE is defined by Sayers et al. [5] to supply education predominantly to nursing staff within a clinical setting. Continuing professional education (CPD) refers to development addressing learner needs and practice competency [2].

In developed countries, CNE was one of the career pathways for nurses in clinical settings. CNE's role in Australia's health care setting changed to the hospital-based system to renders support and facilitate professional learning by practice, which is previously using a hospital-based educator who had a full capacity of nurse education and professional development. They dedicated general work practices both in acute and community-based hospitals [6]. Nurse educators are regularly used in the intensive and emergency ward in acute hospital settings in the UK [7]. In the United States, the requirement for educators that have a graduatelevel of academics. For the past four to five decades, US graduate nursing programs had changed from a focus on nursing administration to education to clinical specialization [8]. The World Health Organization [9] stated that for becoming a nurse educator, a qualified nurse educator must be attained including: completed a recognized nursing education program both theoretical and practical component; holds a current license or registration or other forms of legal recognition to practice nursing; have a minimum of 2 years full-time clinical experience across the scope of practice within the last 5 years; have formal educational teaching preparation before or after employment as a nurse educator.

\section{The role of nurse educator}

The Australian Nursing Federation [2] stated the scope of roles for the CNE including (1) using creative and inventive strategies to promote a learning environment that supports flexible opportunities based on learners, (2) enables professional development and competence by providing education and assessment of learners' priorities and clinical skills, (3) CNE develops and implements collegial networks maturely and effectively to produce positive learning outcomes for clinical staff, (4) All the relevant stakeholders are held accountable by CNE, (5) By showing openness to others, CNE gains confidence and trust in colleagues. CNE takes responsibility for training and service, and faith in action is apparent in the CNE as a role model, (6) Demonstrate the commitment to continuous improvement to maintain ethical practices, and (7) CNE is engaged in activities that show its commitment to the development of the best practices.

Curriculum-design, content development, curriculum, and leadership roles merged with CNEs clinical skills with those of educators, performance evaluation, and recording educational outcomes. Sayers [2] stated that nurse educators had multi-purposes according to the location and the type of service. They lead the staff in combining their theories with practices. They are responsible for continuing education as a mentor or speciality program, for instance, intensive nursing. Nurse educators might work with pupils or registered nurse (RN) staff in teaching bedside, supervising, or evaluating competency. They also conduct orientation and education sessions to address tutoring needs.

\section{Standard requirements of CNE}

The conceptual framework by Benner's novice to an expert framework [10], recommends that confidence levels will increase concurrently as transitions from beginner to expert their knowledge, ability, and critical thinking skills increase [11]. Facilitating the CNE transition program is crucial as it will enable the success to fulfil the nursing's educational needs [7]. Nurse educators have an essential role in nursing professional development education and research development in health care. These roles are embedded in clinical and education. A collaborative between clinical and academic research will offer flexible and innovative teaching practices to achieve clinical skills and competencies [5]. Booth et al. [8] stated that all strategies are required for nurse educators' role and work to be highly valued compared to the graduate level of nurses who work in direct care and indirect care. In Australia, there are no special requirements such as credentialing requirements or training programs to promote RN to CNE. They assumed that RN with proficient skills and experience also have the abilities and knowledge needed for teaching [7].

Sheppard-Law et al. [7] revealed that CNE who participated in educational preparation programs positively impacted their clinical practice. The themes that emerged from this research included the change of CNE practice, functional relationships, and feeling connected. This study described participants increasing their knowing, abilities, and comprehension of EBP. Educational preparation built beneficial relationships between the educator and their mentors, and they had connected feeling and had developed a supportive network with their mentors [12]. 


\section{Challenges of CNE}

Based on Indonesia guidance of clinical practice issued by the Indonesia Department of Health, a clinical educator is someone who has been assigned and charged by a health service or educational institution with the responsibility of guiding students enrolled in clinical practice lessons in hospitals [13]. However, there is no standard requirement to become CNE in Indonesia. The previous study stated the general conditions to be a CNE [14]. Another earlier study found CNE should have nursing competence and pedagogic teaching, evaluation skill, personal factor (attitude and character), and relationship with the student [15]. Thus, CNE is still unclear in Indonesia. Moreover, the lack of literature support in Indonesia makes a big challenge.

CNE is an essential role for nurses in the hospital. However, Conway and Elwin [6] stated CNE is no longer have the particular command; other nursing specialist roles had appeared and implied responsibility for nursing education in the practice area. That impacted the CNE role erosion had significantly. Sheppard-Law et al. [7] studied revealed that nurse educators had challenges mentoring, including time deficiency, ambiguity role, and insuficient education for face-to-face.

\section{Methods}

This study using qualitative methodology with an exploratory study design approach. The research was done at SGH in Bali, Indonesia. Respondents were recruited by using a purposive sampling method. All of the CNEs were invited to participate in the semistructured interview that was conducted in OctoberNovember 2018. CNEs who had experienced clinical teaching at $\mathrm{RDH}$ were 13 nurses. The Researcher act as the interviewer and responses were sought from all participants and recorded. The first researcher is a nursing practitioner at $\mathrm{SGH}$ with experience of more than 10 years. The second, third, and forth are a lecturer of the bachelor, master and doctoral program at Ganesha University of Education. Last researchers is a lecturer of the bachelor nursing program at STIKes Wira Medika Bali.

The researchers made similar perceptions before collecting the data. We agreed with the questions that would be asked the respondent. Some questions with a specific focus on the following include (1) What are positive changes that CNEs have brought to Sanglah? (2) What are the challenges or barriers to successfully implementing the CNEs role? (3) What are the personal benefits have you gained from undertaking the CNEs role?

\section{Data collection}

Oral and written information gave to the respondent related to research, then signing informed consent, and the interviews were held base on scheduled appointments. Interviews were conducted in Bahasa Indonesia or the Balinese language. Three researchers conducted semi-structured interviews ranged between 60 and $120 \mathrm{~min}$ and two researchers checked the saturation of the data. Each interview transcripted and analyzed. All of the researchers reviewed the result of the analyses. The interview took place in the central meeting room at $\mathrm{SGH}$ to evade disturbances during the interview. Interviewers used audio-recording, then transcribed verbatim, also validated by researchers with re-listening.

\section{Data analysis}

The qualitative content analysis technique was applied in this investigation [16], [17] to summarize the content data, including visual and verbal. The recorded discussions from each participant were transcribed into text. The pertinent data were segmented into many lines of code and compared between participants. Those with the same detail were merged and recoded. Then, based on the code connection, we created a diagram that linked between participants.

Trustworthiness was approached through internal member checking by the interviewer and by faceto-face verification of participants [18]. Peer-review used an experienced researcher to examine and compare the data quality. Bracketing assured by communicating between researchers regarding personal biases and experiences with the study topic [19]. Moreover, the researchers saved record traces and notes regarding interpretive decisions. Finally, for ensuring the translation to English is consistent with what the participant said, researchers re-checked and compared from recorded and transcribed.

\section{Ethical considerations}

SGH granted ethical approval number 376/ UN.14.2/KEP/2018 with the Director of SGH providing written consent. The purpose and beneficiary of the study were informed to the participant. Participants were allowed to withdraw. Their data would be protected and anonymized. Finally, without coercion, the participants read and signed a consent document voluntarily.

\section{Results}

A total of eight CNE participated in the focus group as a follow-up study of CNE evaluation 
at SGH. Overall, participants described their experience in a CNE role is decisive. Four themes emerged positive experience as CNE, including (1) continuing professional development, (2) role model, (3) valued and trust, and (4) motivated to learn. Challenges as CNE there were four themes emerged including (1) Lack of management support, (2) educational preparation, (3) ambiguity role, and (4) CNE ratio.

\section{Benefits of CNE role}

\section{Continuing professional development}

The participant said how their role as CNE could bring positive benefit for other nurses to improve knowledge and skill capacity through continuing professional development.

"Policies and procedures are sustained implemented due to regular re-socialization" (participant 1)

"The CNE's very helpful to improve nurses and midwives knowledge and skill capacity, many programs about CPD, help the nurses from doing Plan, Act, Do, Check, and Evaluation." (Participant 2)

"Refresh about the latest information about how to care obstetric patients." (participant 7)

"I can educate all of the chemotherapy nurses to do the job with the right procedures." (Participant 3)

"Happy to share knowledge for nurses can give socialization with fellow nurses." (participant 4)

"Continuing Profesional development are conducted regularly by CNE in many ways of teaching and learning in the clinical setting. CNE develop nursing grand round routinely each month, we also conduct in house training and bedside teaching to increase clinical skill nurses." (participant 5)

"Socialization about how to fill out form almost for all staff nurse or midwife in the hospital." (participant 6)

"The nurses get new knowledge about things given by CNE in the nursing grand round, in house training." (participant 8).

\section{Role model}

A clear impression emerged that participants believe they are role models for other nurses and that their actions in the clinical context will be praised by other nurses.

"Learning as a role model for nurses friend." (participant 4) "we as Sanglah hospital nurses already initiated to lead when there is a problem of within nursing" (participant 4)

"To continue to develop owns skills both knowledge and skill so they can be role model for other nurses" (participant 5).

\section{Valued and trust}

As part of CNE roles, participants think that they were valued and confident by other nurses; hence they gain self-confidence and satisfaction.

"We are quite proud of taking this role, and this brings about self-satisfaction as staff." (participant 8)

"I can increase self-confidence." (participant 5)

"More valued and trusted in provide learning to the nurse." (participant 8).

\section{Motivated to learn}

Competent CNE required to update themself with enormous knowledge. They will become motivated to fulfill themself with updated skills and knowledge to fit in their role.

"I have many friends and officials. I have motivations to improve my knowledge." (participant 2)

"First and foremost, we must update ourselves to fit in the CNE role; and this is by brings about personal, professional improvement" (participant 1)

"I am pleased to be CNE because I can improve myself and always learn, and learn" (participant 3)

"I am happy because I can get motivated other nurses to do their job well" (participant 3).

\section{Challenges of CNE role}

Because many hospital administrators are unfamiliar with the job of a CNE, most participants found it difficult to perform CPD in the clinical context as various issues arose.

\section{Lack of management support}

Participants described that management is not supported CNE activity including office facilities where they can prepared teaching and learning material.

"Management has to understand what CNE $\mathrm{s}$, what is the Role of CNEs, and support all CNEs activity" (participant 2)

"Support of nursing management is not 
maximized" (participant 4)

"Facilities incomplete owned by CNE to provide learning "(participant 8)

"Need socialization to management CNE role" (participant 3).

\section{Educational preparation}

Participants think that they also need educational qualification about $\mathrm{CNE}$, and they need also training from outside hospital.

"Continues Sister Hospital Program, give trained or course all about CNE Role." (participant 3)

"CNE needs to regularly attend the external continuous professional development." (participant 1).

\section{Ambiguity role}

Most participants described that they felt their roles were ambiguous and that they could ultimately not act on this position.

"CNE still working each area and serving patients so that their work can not be maximal CNE" (participant 4)

"This moment if we have CNE meeting/Nursing Grand Rounds, they can not attend it, since no one can replace their job at the patient care, yet they can not come for the meeting." (participant 5)

"still give patient care directly" (participant 6)

"still providing services to patients and could not devoting time to the development of staff' (participant 7)

"not fully work CNE because much other work outside CNE task" (participant 8).

\section{CNE ratio}

There was a discrepancy between the number of nurses and the number of CNEs available at SGH, resulting in a lack of effective teaching and learning.

"CNEs In Sanglah Hospital still not enough ratio, 1500 nurses work in Sanglah Hospital but the CNE just 10" (participant 2)

"CNE Sanglah Hospital still not many, so it needs to be added to the CNE team and more area CNE" (participant 4)

"The number of CNE still less than total staff/ the nurse at the hospital" (participant 6)

"the ratio CNE and nurses not in equal proportions" (participant 7)
"Ratio CNE and the number of nurses unbalanced" (participant 8).

\section{Discussion}

This study described the CNE of the SGH experience of their role in the clinical setting. Themes emerged from participants' benefit for undertaking CNE roles for personal and hospital, including CPD, role model, valued and trust, and motivation to learn. The findings were consistent with the study of Sheppard-Law et al. [7], the benefits of the CNE role included that they experience a beneficial relationship as mentor and mentee, including positive energy, assistance, non-judgmental, classified, and safe. The CNEs at SGH also described feeling connected, also represented by Conway and Elwin [6]. The CNE role in the system hospital-based CNE is crucial in supporting fresh graduated and experienced nurses for applying formal learning in clinical practice. It also committed their expertize totally to develop the continuing professional development of nursing staff in clinical practice. CNE had built a relationship for other nurses that considerable as positive and mutual. Findings from this study were that most participants were motivated to learn. This finding is supported by Sayers [2] and Råholm et al. [20] that educators are clinical experts and expert educators, grasping academic theory and principles to integrate the expertize and experience in applying their clinical practice [21]. Specific role required specific education qualifications and expert verification, and the education needed to realize the expertize [4], [16]. CNE also requested to continuing their knowledge in some areas such as cardiology, pediatric expert, and other experience.

The findings from this study found challenges as CNE there were four themes emerged, including (1) lack of management support, (2) educational preparation, (4) ambiguity role, (5) CNE ratio. These findings are similar to those reported by Sayers [2] and Alghamdi et al. [22] found that role identity, ambiguity, and conflict are barriers to successfully undertaking this role. CNEs required knowledge and expertize in education systems to notify their practice, for instance, critical thinking, clinical leadership, culture, communication skills, reflection, and commitment to learning [23]. They also needed teaching processes for CNEs to perform successfully. Other studies found time deficiency, ambiguity role, and insuficient education for face to face. Made the role of challenging [2], [7], [24]. Sayers [2] concluded that remuneration also needs to be included as it was important for CNE.

Inadequate CNEs-students ratio would increase workload and reduce time constraints, making CNEs feel struggling to teach ineffective and efficient [25]. The hospital could increase the number 
of CNEs, but it will spend time and cost. Another alternative that gives a congruence policy supports the CNEs roles [26].

Management support, specifically hospital, has an integral part of implementing the CNEs roles. It has sometimes been politically challenging to instigate and maintain reform and get the workers on board to work on some problems. Without assistance at all levels, from service directors to ward sisters, this is nearly impossible [25], [26], [27]. Supportive management is needed because of CNEs' roles, including CPD, professional regulation, risk management, and a safeguard in the clinical environment [26].

It is possible that there may be a bias if we ask from the perspective of hospital's higher management as a result of the study's methodological flaws. Besides, the study was conducted at tertiary hospital that would make a difference with secondary or primary hospital because different standard. Another limitation that the findings could not be generalized due to the possibility that participants' perceptions might be swayed by factors such as their work environment and personal characteristics. Further study needs to test these factors related to implementation of CNE.

\section{Conclusion}

Four themes emerged from this study, including positive experience as CNE (1) CPD, (2) Role Model, (3) valued and trust, (4) motivated to learn. Challenges as CNE there were four themes emerged, including (1) lack of management support, (2) educational preparation, (3) ambiguity role, (4) CNE ratio. Hence, the development of the CNE role in hospital learning and mentoring programs is recommended.

It required a series of crucial skills to the successful implementation of the role as an educator. The benefit of CNE is enormous for nursing staff that would help nurse educator develop their leadership character that includes role model, be trusted, valuable, motivated. Moreover, it would impact other nursing staff and students, such as motivation to learn and following the role model. Therefore, the implication for future novice CNE is that they need to have effective preparatory learning programs.

Further, it is crucial that the hospital management actively and practically support their role included a policy of roles of CNE, career pathway, and standard of competence being a CNE. The CNE roles outline policy explains the ratio minimum and maximum of educator-student, educator authorities, and educator competence. The career pathway of CNE should in line with their specialties that would make a benefit for nursing.

\section{References}

1. World Health Organization. Nurse Educator Core Competencies. Geneva: World Health Organizations; 2016. p. 1-30. Available from: $\quad$ https://www.who.int/hrh/nursing_midwifery/nurse educator050416.pdf. [Last accessed on 2019 May 31]

2. Sayers JM. The Role of the Nurse Educator in Acute Care Hospitals, Australia. Australia: Curtin University; 2013.

3. Kementerian Kesehatan RI. Pengembangan Jenjang Karir Profesional Perawat Klinis. Indonesia: BN.2017/NO.1129, kemenkes.go.id: 5 hlm. Jakarta: Kementerian Kesehatan Rl; 2017.

4. Nuryani SN, Wati NM, Juanamasta IG. Nursing grand rounds (NGRS) regularly to encourage continuing professional development (CPD) achievement of nurses. Pak J Med Health Sci. 2020;14(4):1616-8.

5. Sayers JM, DiGiacomo M, Davidson PM. The nurse educator role in the acute care setting in Australia: Important but poorly described. Aust J Adv Nurs. 2011;28(4):44-52.

6. Conway J, Elwin C. Mistaken, misshapen and mythical images of nurse education: Creating a shared identity for clinical nurse educator practice. Nurse Educ Pract. 2007;7(3):187-94. https:// doi.org/10.1016/j.nepr.2006.08.005

PMid: 17689443

7. Sheppard-Law S, Curtis S, Bancroft J, Smith W, Fernandez R. Novice clinical nurse educator's experience of a self-directed learning, education and mentoring program: A qualitative study. Contemp Nurse. 2018;54(2):208-19. https://doi.org/10.1080/10 376178.2018.1482222 PMid:29871554

8. Booth TL, Emerson CJ, Hackney MG, Souter S. Preparation of academic nurse educators. Nurse Educ Pract. 2016;19:54-7. https://doi.org/10.1016/j.nepr.2016.04.006 PMid:27428693

9. Groves PS, Manges KA, Scott-Cawiezell J. Handing off safety at the bedside. Clin Nurs Res. 2016;25(5):473-93. https://doi. org/10.1177/1054773816630535

\section{PMid:26858262}

10. Ulrich B. From novice to expert. Nephrol Nurs J. 2011;38(1):9.

11. Brown T, Sorrell J. Challenges of novice nurse educator's transition from practice to classroom. Teach Learn Nurs. 2017;12(3):207-11.

12. Summers JA. Developing competencies in the novice nurse educator: An integrative review. Teach Learn Nurs. 2017;12(4):263-76. Available from: https://linkinghub.elsevier. com/retrieve/pii/S1557308717300173

13. Pusdiknakes RI. Pengelolaan Pembelajaran Praktek Klinik. Jakarta Dep Kesehat RI. 2004;

14. Nursalam N, Efendi F. Pendidikan Dalam Keperawatan [Education in Nursing]. Salemba Medika; 2008.

15. Astuti VW, Kusumawati W, Afandi M. Kompetensi Pembimbing Klinik dalam Proses Pembelajaran di Klinik [Clinical Supervisor Competency in Learning Process at the Clinic]. J Penelit Keperawatan. 2016;2(2):119-129. Available from: https://doi. org/10.32660/jurnal.v2i2.135.

16. Wati NM, Lestari RT, Ayuningtyas G, Ardi NB, Juanamasta IG. Nurse perceived of caring leadership: A qualitative descriptive study. Open Access Maced J Med Sci. 2021;9(G):88-93.

17. Yamamoto-Mitani N, Saito $\mathrm{Y}$, Takaoka M, Takai $\mathrm{Y}$, Igarashi $\mathrm{A}$ Nurses' and care workers' perception of care quality in japanese long-term care wards: A qualitative descriptive study. Glob Qual Nurs Res. 2018;5:233339361881218. https://doi. org/10.1177/2333393618812189

18. Gunawan J. Ensuring trustworthiness in qualitative research Belitung Nurs J. 2015;1(1):10-1. https://doi.org/10.33546/bnj.4. 
19. Aungsuroch Y, Juanamasta IG, Gunawan J. Experiences of patients with coronavirus in the COVID-19 pandemic era in Indonesia. Asian J Public Opin Res. 2020;8(3):377-92. https:// doi.org/10.15206/ajpor

20. Råholm MB, Löfmark $A$, Henriksen J, Slettebø A. Nurse education role complexity and challenges. Int J Hum Caring. 2016;20(2):76-82. https://doi.org/10.20467/1091-5710-20.2.76

21. Juanamasta IG, Iblasi AS, Aungsuroch $Y$, Yunibhand J. Nursing development in Indonesia: Colonialism, after independence and nursing act. SAGE Open Nurs. 2021;7:237796082110514. https://doi.org/10.1177/23779608211051467

22. Alghamdi R, Albloushi M, Alzahrani E, Aldawsari A, Alyousef S. Nursing education challenges from saudi nurse educators' and leaders' perspectives: A qualitative descriptive study. Int J Nurs Educ Sch. 2019;16(1):27. https://doi.org/10.1515/ijnes-2018-0027 PMid:30798324

23. Grassley JS, Lambe A. Easing the transition from clinician to nurse educator: An integrative literature review. J Nurs Educ. 2015;54(7):361-6. https://doi. org/10.3928/01484834-20150617-01

\section{PMid:26155026}

24. Jasemi M, Whitehead B, Habibzadeh H, Zabihi RE, Rezaie SA Challenges in the clinical education of the nursing profession in Iran: A qualitative study. Nurse Educ Today. 2018;67:21-6. https://doi.org/10.1016/j.nedt.2018.04.010 PMid:29727826

25. Younas A, Zeb H, Aziz SB, Sana S, Albert JS, Khan IU, et al. Perceived challenges of nurse educators while teaching undergraduate nursing students in Pakistan: An exploratory mixed-methods study. Nurse Educ Today. 2019;81:39-48. https://doi.org/10.1016/j.nedt.2019.07.002 PMid:31323505

26. Brennan AM, Hutt R. The challenges and conflicts of facilitating learning in practice: The experiences of two clinical nurse educators. Nurse Educ Pract. 2001;1(4):181-8. https://doi. org/10.1054/nepr.2001.0031

PMid:19036261

27. Arini T, Juanamasta IG. The role of hospital management to enhance nursing job satisfaction. Indones Nurs J Educ Clin. 2020;5(1):82-6. https://doi.org/10.24990/injec.v5i1.295 